\section{FATORES DA QUALIDADE PERCEBIDA RELACIONADOS AO VALOR PERCEBIDO DO PREÇO EM SUPERMERCADOS COMPACTOS}

\section{FACTORS OF PERCEIVED QUALITY RELATED TO PERCEIVED PRICE VALUE IN COMPACT SUPERMARKETS}

\section{RESUMO}

O setor supermercadista brasileiro possui baixas barreiras de entra$\mathrm{da}$, forçando os micros e pequenos supermercados a se modernizarem para oferecer qualidade superior nos serviços. O objetivo deste artigo foi identificar a influência da qualidade percebida sobre o valor percebido do preço do produto no processo de desenvolvimento da vantagem competitiva em supermercados compactos. Dados foram coletados com 160 clientes, distribuídos em quatro supermercados compactos na Cidade de Goiás (GO). Por meio da técnica de análise de regressão linear múltipla, verificou-se que os fatores da qualidade percebida, significativamente, relacionados ao valor percebido do preço do produto, foram aspectos tangíveis, responsividade, empatia e localização. As evidências apontam um nível de qualidade percebida semelhante aos supermercados pesquisados, levando a concluir que os aspectos analisados não podem ser considerados diferenciais estratégicos que conduzam a vantagem competitiva. Esta pesquisa contribui ao demonstrar que as atuais estratégias para geração de valor no setor precisam ser revisadas.

Palavras-chave: Supermercado. Qualidade Percebida. Valor Percebido. Vantagem Competitiva.

\begin{abstract}
The Brazilian supermarket sector has low entry barriers, forcing micro and small supermarkets to modernize themselves to offer superior quality in services. This article aims to identify the influence of perceived quality over perceived value of product price in the process of developing competitive advantage in compact supermarkets. Data were collected with 160 customers, distributed in four compact supermarkets in the city of Goiás (GO). Through the multiple linear regression analysis technique, it was found that
\end{abstract}


the factors of perceived quality significantly related to the perceived value of the product price were: tangible aspects, responsiveness, empathy and location. The evidence points to a level of perceived quality similar to that of the supermarkets surveyed, leading to the conclusion that the aspects analyzed cannot be considered strategic differentials that lead to competitive advantage. This research contributes by demonstrating that the current strategies for value generation in the sector need to be reviewed.

Keywords: Supermarket. Perceived Quality. Perceived Value. Competitive Advantage.

\section{INTRODUÇÃO}

No início dos anos 1990, os empresários brasileiros presenciaram o acirramento da competição no mercado interno provocado pela chegada de empresas estrangeiras ao Brasil (FLORIANI, 2010). Esse evento gerou, no setor de supermercado, uma concentração de mercado de grandes grupos internacionais e nacionais (WERNER; SEGRE, 2001). Para adquirirem participação de mercado, os micros e pequenos supermercados formaram redes cooperativas e investiram em qualificação de pessoal, tecnologia da informação e prestação de serviços (GARCIA, 2011; HALFIN, 2007). Também houve uma tendência de transformação das lojas com apenas um caixa (check out) - que realizavam baixos investimentos em tecnologia de vendas para o varejo e em conforto - para supermercados classificados como compactos com investimentos na busca por eficiência operacional e técnica, cujas principais características são áreas de vendas entre $300 \mathrm{e}$ $700 \mathrm{~m}^{2}$ e existência de 2 a 6 check outs (TOALDO; ABEL SOBRINHO; CAMARGO, 2010).

O setor supermercadista brasileiro vem registrando, ao longo do tempo, saldos positivos em diversos indicadores. Entre 1994 e 2019, o faturamento no setor cresceu $88,07 \%$ e, entre 1999 e 2019, o número de lojas saiu de 55 mil para 89,8 mil, crescimento de $63,27 \%$ (NUNES FILHO, 2019). Com um faturamento no setor de R\$ 378,3 bilhões em 2019, tal crescimento no número de lojas significa mais competição. Atualmente, os supermercados compactos responderam por $92,9 \%$ do faturamento no setor (NUNES FILHO, 2019).

Em contextos de competitividade, o papel do empreendedor é alinhar as estratégias com as demandas do mercado e gerar boas performances sustentáveis no tempo (SALUNKE; WEERAWARDENA; MCCOLL-KENNEDY, 2011). Assim, embora atributos, como atendimento, atmosfera de loja, qualidade, variedade e localização sejam importantes à geração de vantagem competitiva (HERMES; CRUZ; SANTINI, 2016), o empreendedor deve saber que o preço é uma variável fundamental para gestão de marketing (BOLTON; WARLOP; ALBA, 2003).

A geração de vantagem competitiva, em um setor competitivo e de baixas barreiras quanto o de supermercados, deve vir do valor que a empresa cria aos seus clientes. Com efeito, este artigo propõe que a qualidade percebida pelos clientes de supermercados compactos independentes (não pertencem a redes e não são filiais de grandes empresas) influencia o valor percebido do preço do produto, e, consequentemente, de sua relação com preço, surge a decisão de compra, levando, assim, à vantagem competitiva (MONROE, 1990; AILAWADI; KELLER, 2004; BLACKWELL; MINIARD; ENGEL, 2005).

O problema de pesquisa que se buscou responder foi: quais os fatores da qualidade percebida que geram valor percebido do preço do produto e colaboram para o desenvolvimento da vantagem competitiva em supermercados compactos? O objetivo do artigo foi identificar a influência da qualidade percebida sobre o valor percebido do preço do produto no processo de desenvolvimento da vantagem competitiva em supermercados compactos.

A qualidade percebida é explorada nesta pesquisa por meio da escala ServQual (PARASURAMAN; ZEITAML; BERRY, 1985) em cinco dimensões: elementos tangíveis, responsividade, confiabilidade, segurança, empatia, e, 
também, pela variável localização. O valor percebido do preço do produto é explorado nesta pesquisa por meio da escala composta por seis itens desenvolvida por De Toni e Mazon (2014).

Decidiu-se proceder à análise das hipóteses por meio da técnica de análise de regressão múltipla, que permite verificar, simultaneamente, todas as hipóteses levantadas, além de verificar a importância relativa de cada uma delas sobre o valor percebido do preço do produto no processo de desenvolvimento da vantagem competitiva em supermercados compactos (HAIR et al., 2005). Por meio da técnica de tabela cruzada, os pesquisadores realizaram o cruzamento dos supermercados com as variáveis independentes da pesquisa para verificação dos níveis de qualidade percebida. A pesquisa foi realizada na Cidade de Goiás (GO) com uma amostra de 160 clientes abordados em quatro supermercados compactos.

Por comercializar gêneros de primeira necessidade, os supermercados tornaram-se imprescindíveis ao bem-estar social, além de referência para análise do varejo (FERREIRA, VENÂNCIO; ABRANTES, 2009). Por esse motivo, pesquisas anteriores buscaram contribuir para a discussão teórica da vantagem competitiva dos micros e pequenos supermercados (QUEIROZ; SOUZA; GOUVINHAS, 2008; COLLA et al., 2013; DALONGARO; PIRES; FROEMMING, 2015). Porém, esses trabalhos não esgotaram a necessidade de aprofundar o entendimento do tema da vantagem competitiva no setor.

As Micros e Pequenas Empresas (MPEs) têm bastante importância para as pesquisas acadêmicas, quanto para o desenvolvimento da economia, em grande parte devido à sua capacidade de geração de mão de obra ocupada e contribuição no Produto Interno Bruto (PIB) (SANTOS; KREIN; CALIXTRE, 2012). Com efeito, considera-se importante estudar o valor percebido, pois os gestores devem identificar o nível de percepção dos clientes quanto à efetividade das estratégias que estão sendo elaboradas nas organizações, uma vez que esse entendimento é fundamental à manutenção do negócio (WOERTER; ROPER, 2010).

A fundamentação teórica da pesquisa define supermercado e apresenta o conceito de vantagem competitiva. Em seguida, aborda o conceito de qualidade e apresenta a escala SERVQUAL. Na sequência, aborda o conceito de valor percebido e o desenvolvimento da escala do valor percebido do preço do produto. No terceiro capítulo, estão os procedimentos metodológicos. O quarto capítulo apresenta a análise dos fatores e a discussão dos resultados. Por fim, é apresentada a conclusão da pesquisa.

\section{FUNDAMENTAÇÃO TEÓRICA}

\subsection{O SETOR DE SUPERMERCADOS E A VANTAGEM COMPETITIVA}

Supermercado pode ser definido como "um varejo generalista que revende ao consumidor final ampla variedade de produtos, disposto, de forma departamental, no sistema de autosserviço." (SILVEIRA; LEPSCH, 1997, p. 6). Por trabalharem com gêneros de primeira necessidade, os supermercados tornaram-se imprescindíveis à comodidade da sociedade (FERREIRA; VENÂNCIO; ABRANTES, 2009). Os supermercados modernos sugiram no início do século XX (CONNOR; SCHIEK, 1997); contudo, o modelo de negócio de autosserviço no estilo pegue e pague somente chegou ao Brasil nos anos 1950, e, logo na década de 1960, essa forma de comercialização se tornou importante para o varejo de alimentos (BNDES, 1996; SESSO FILHO, 2003), de forma que, no início dos anos 1970, o setor representava $26 \%$ das vendas de gêneros alimentícios (ROJO, 1998) e, no final da década de 1980, respondiam por $82,6 \%$ dos bens de consumo diário no país (WILDER, 2003).

No início dos anos 1990, os entrantes varejistas internacionais acirraram a competição nacional ao adotarem o conceito de lojas de vizinhança, operando com estrutura física e organizacional menor e mais simples que a dos hipermercados (GENNARI, 2002). Surgem os supermercados compactos, que têm como carac- 
terísticas área de vendas entre 300 e $700 \mathrm{~m}^{2}$, possuir entre 2 a 6 chekouts e o percentual de venda de alimentos representar mais que $95 \%$ do faturamento da loja (SESSO FILHO, 2003; TOALDO; ABEL SOBRINHO; CAMARGO, 2010).

Em tempos de competitividade, o papel do empreendedor é analisar os ambientes organizacionais internos e externos, a fim de alinhar as estratégias às expectativas do mercado e gerar boas performances sustentáveis (GUEDES et al., 2016). A vantagem competitiva acontece quando uma empresa gera maior valor econômico do que as empresas concorrentes (BARNEY; HESTERLY, 2007), ou seja, quando uma empresa se posiciona acima da média em relação a si mesma, em anos anteriores, e às demais empresas com as quais compete, por meio de reconhecimento e criação de valor de seus stakeholders (BARBANTE et al., 2012; BRITO; BRITO, 2012; PITELIS, 2009).

Entre 2012 e 2018, o número de lojas de supermercados no Brasil cresceu em uma taxa média de $1,2 \%$ ao ano, visto que os supermercados com dois ou mais check outs responderam por $92,9 \%$ do faturamento registrado em 2018 (NUNES FILHO, 2019). A vantagem competitiva observada nos supermercados compactos perante as grandes lojas é a proximidade de relacionamento que estabelecem com os consumidores, já que podem "se adequar melhor à variedade de produtos, buscando eficiência na comercialização de produtos de maior conveniência, principalmente perecíveis." (SESSO FILHO, 2003, p. 43).

A geração de vantagem competitiva em um setor competitivo e de baixas barreiras quanto o de supermercados deve vir do valor que a empresa cria aos seus clientes em oposição aos custos incorridos para criá-lo, de forma que, independentemente do posicionamento estratégico adotado (custo, foco, diferenciação), a disputa será pela geração de valor (PORTER, 1980, 1985), por outro lado, Vasconcelos e Cyrino (2000, p. 24) indicam "vantagem competitiva é o resultado da capacidade da firma em realizar, eficientemente, atividades, obtendo, dessa maneira, menores custos do que seus concorrentes". De maneira ou outra ou complementarmente, vantagem competitiva se garante ao obter posição privilegiada (VASCONCELOS-DA-SILVA; BARBOSA, 2002).

Os supermercados vêm desde a década de 1990, reestruturando-se de maneira organizacional e estratégica, buscando qualidade e oferta de mix de produtos e, também agregando valor aos serviços (BARROS, 2007). Os gestores vêm adotando estratégias competitivas na busca por excelência na qualificação dos colaboradores e inovação na oferta de produtos e serviços, como identificação de produtos por radiofrequência (RFID), e-commerce e transações financeiras com clientes (web banking) com o intuito de gerar fidelização (WERNE; SEGRE, 2001; ABRAS, 2013), mas também investimentos em mecanismos de gestão e controle (uso de tecnologia da informação).

\subsection{CONCEITO DE QUALIDADE E A ESCALA SERVQUAL}

A definição de qualidade é subjetiva (MACOWSKI, 2007). Contudo, ela reflete a maneira como as organizações conduzem a produção de bens e serviços (HOFFMANN, 2006). As percepções da qualidade do serviço são afetadas pelo que é fornecido, bem como pela maneira como o cliente é tratado, quando o serviço é realizado (SANTOS; ROSALEM, 2006). Com efeito, o valor atribuído à qualidade torna-se função do nível de conformidade do que é esperado a um custo aceitável (GARVIN, 1992).

$\mathrm{Na}$ era da competitividade, o prestador de serviço se destaca pela oferta na qualidade na prestação de serviços, tornando esse um fator capaz de gerar vantagem competitiva (HOFFMANN, 2006). Dessa maneira, ao prestar serviços de qualidade, consegue-se superar as expectativas dos clientes, que são formadas por experiências passadas e, principalmente, pela propaganda boca a boca (SANTOS; ROSALEM, 2006).

A qualidade do serviço é determinada pela maneira como este é feito, impactando 
na percepção do cliente e justificando sua impressão (MACOWSKI, 2007). Para Hoffmann (2006, p. 51), "a qualidade nos serviços possui, portanto, dois componentes: o serviço propriamente dito e a forma como é percebido pelo cliente". Assim, a expectativa do cliente é importante, pois influencia o processo de escolha pelo serviço (HOFFMANN, 2006).

$\mathrm{Na}$ busca por um bom atendimento aos clientes, os empreendedores, constantemente, procuram alternativas para melhorar a qualidade dos serviços (MACOWSKI, 2007). Neste aspecto, o modelo ServQual (PARASURAMAN; ZEITHAML; BERRY, 1985) ajuda a entender qual o nível da qualidade do serviço, e como este é percebido pelos clientes e empresas, medindo a diferença entre as expectativas desses atores para excelência e suas percepções do serviço prestado. Conforme Parasuraman, Zeithaml e Berry (1985), a escala ServQual permite aos prestadores de serviços entenderem as expectativas dos clientes e suas percepções de serviços específicos, proporcionando entendimento necessário à realização de melhorias de qualidade ao longo do tempo.

A escala ServQual considera cinco dimensões como sendo as mais importantes para a avaliação da qualidade de serviços prestados, conforme apresentadas no quadro 1. sobre as expectativas do cliente; a falha 2 é diferença entre as percepções da gerência sobre as expectativas do cliente e as especificações de qualidade do serviço; a falha 3 é diferença entre as especificações de qualidade do serviço e o serviço realmente entregue; a falha 4 é a diferença entre a prestação de serviços e o que é comunicado sobre o serviço aos clientes; e a falha 5 consiste na diferença entre as expectativas e percepções do cliente, sendo essa última considerada a mais importante. A empresa deve preocupar-se em dirimir essa falha, uma vez que ela é o contato final do cliente em relação à percepção do serviço.

Levando em consideração as dimensões abordadas e as falhas percebidas em relação à expectativa e à percepção dos serviços, Parasuraman, Zeithaml e Berry (1985) criaram a Escala ServQual para mensurar a qualidade do serviço. Ela é dividida em duas partes de vinte e dois itens cada. A primeira parte busca medir a qualidade do serviço da empresa e a segunda, com os mesmos itens, busca medir a percepção do cliente sobre o serviço oferecido.

Entre as cinco dimensões abordadas, os clientes consideram as dimensões confiabilidade e tangibilidade como sendo mais e menos importante respectivamente (PARASURAMAN; BERRY; ZEITHAML, 1991). Os auto-

Quadro 1 - dimensões do modelo ServQual

\begin{tabular}{|l|l|}
\hline \multicolumn{1}{|c|}{ Dimensão } & \multicolumn{1}{c|}{ Definição } \\
\hline Elementos tangíveis & $\begin{array}{l}\text { Aparência de instalações físicas, qualidade dos equipamentos, pessoal e } \\
\text { materiais de comunicação. }\end{array}$ \\
\hline Confiabilidade & Capacidade de executar o serviço prometido de maneira confiável e precisa. \\
\hline Responsividade & Disposição de ajudar os clientes e fornecer um serviço rápido e atendimento ágil. \\
\hline Segurança (ou garantia) & $\begin{array}{l}\text { Conhecimento e cortesia dos funcionários e sua capacidade de inspirar } \\
\text { confiança. }\end{array}$ \\
\hline Empatia & $\begin{array}{l}\text { Atenção que a empresa oferece a seus clientes de maneira individualizada e } \\
\text { com qualidade. }\end{array}$ \\
\hline
\end{tabular}

Fonte: Parasuraman, Berry e Zeithaml (1991, p. 423).

Parasuraman, Berry e Zeithaml (1991) elaboraram cinco hipóteses quanto a distância entre a expectativa criada pelo cliente em relação ao serviço e como ele realmente é percebido. A falha 1 é a diferença entre as expectativas do cliente e as percepções da gerência res ressaltam ainda que, mesmo a escala tendo sido desenvolvida para um determinado setor, ela pode ser adaptada e utilizada em outros setores que prestam serviços desde que sejam feitas as alterações necessárias (PARASURAMAN; ZEITHAML; BERRY, 1985). 


\subsection{VALOR PERCEBIDO DO PREÇO}

A importância do construto valor é fundamental para a geração de vantagem competitiva. A geração de valor é a busca contínua das empresas, estando relacionada ao modo como elas realizam suas estratégias para atender às necessidades de clientes em relação a produtos e serviços (ITO et al., 2012). Seu conceito possui diferentes sentidos (TOLEDO; MORETTI, 2016), sendo composto de funcionalidade, qualidade, preço e tempo, formando os atributos do produto ou serviço, somado a imagem e relacionamento (KAPLAN; NORTON, 1997).

O conceito de valor parte da ideia de valor de uso e valor de troca proposto por Adam Smith (SMITH, 1976). Em um sistema capitalista, o valor de uso é determinado pelas características próprias do artefato e pelo uso específico e concreto que se dá a ele por essas características. O valor de troca depende da magnitude determinada pela quantidade de trabalho socialmente necessário para produzir o bem (CARCANHOLO, 1998).

Se algo é abundante, não há valor de troca, mas sua escassez garante alto valor. Assim, o dinheiro passa a ter alto valor percebido em uma relação de consumo quando rara for sua posse e elevado for o preço do bem ou do serviço. Assim, "o preço real de cada coisa para o homem é o trabalho e o sacrifício que ele tem para sua aquisição. Logo, é caro o que é difícil de conseguir, ou aquilo que custa muito trabalho para adquirir; e é barato aquilo que pode ser conseguido facilmente ou com muito pouco trabalho." (DE TONI; MAZON, 2013, p. 455).

A percepção de valor tem relação direta com sacrifício (preço) e benefício (qualidade) no processo de compra (DE TONI; MAZON, 2013), mas não é adequado simplificar a análise da variável preço somente enquanto componente monetário. O componente sociopsicológico amplia o conceito de valor ao atuar na relação entre custos e benefícios monetários e não monetários, de forma que, "quando o cliente paga um preço justo pelo benefício recebido, sua intenção de (re) compra tende a aumentar." (DE TONI; MAZON, 2013, p. 457).

Valor é aquilo pelo qual os clientes estão dispostos a pagar por produtos ou serviços que são oferecidos, em uma relação entre os benefícios esperados pelo produto ou serviço e o custo gerado para adquiri-lo (PORTER, 1980, 1985). Assim, valor passa a ser um "atributo que dá aos bens materiais sua qualidade de bens econômicos." (SANDRONI, 1999, p. 625).

Contudo, a condição que anula a tomada de decisão por compra como resultado da relação custo $\mathrm{x}$ benefício é quando não há diferenças perceptíveis na qualidade dos produtos ou serviço oferecidos. Consequentemente, não existirá troca de fornecedor por parte do consumidor, já que o resultado provável para essa decisão é o aumento da percepção do sacrifício monetário incorrido pela troca (DE TONI; MAZON, 2013).

Depreende-se, assim, que a variável preço determina valor, que, por sua vez, quanto maior o valor tangível e intangível a empresa entregar para seus consumidores, maiores os níveis de preço que ela pode praticar (THEODORIDIS; CHATZIPANAGIOTOU, 2009). A relação preço x valor varia ao longo de um continuum, desde a percepção simples de que preço é fator determinante, até o entendimento de um complexo processo sociopsicológico de sacrifício x benefício percebido pelo consumidor (DE TONI; MAZON, 2013).

O valor percebido do preço é formado por um conjunto de representações mentais, impressões, convicções e redes de significados armazenadas na memória dos consumidores, sendo definido "como uma variável latente impactada por dimensões que traduzem uma convicção subjetiva, funcional, social, epistêmica, emocional e condicional associada ao preço de um produto ou serviço." (DE TONI; MAZON, 2014, p. 551).

De Toni e Mazon (2014) criaram uma escala composta por seis itens para mensurar valor percebido do preço de produto (Quadro 8 da sessão procedimentos metodológicos). Os procedimentos de validação da escala realiza- 
dos por eles foram avaliação de face e conteúdo por dois experts na área; ajustes necessários de indicadores de confiabilidade calculados junto a duas amostras de 114 e 45 consumidores, respectivamente. Por fim, os pesquisadores procederam à análise da validação e confiabilidade da escala purificada com base em outra amostra composta por 337 consumidores, por meio da técnica de modelagem de equações estruturais, entregando, assim, uma escala satisfatória (DE TONI; MAZON, 2014).

\section{PROCEDIMENTOS METODOLÓ- GICOS}

Este capítulo descreve os passos percorridos pelos autores para identificar quais os fatores da qualidade percebidos que geram valor percebido do preço do produto e colaboram para o desenvolvimento da vantagem competitiva em supermercados compactos. A fase inicial consistiu em procedimentos exploratórios e permitiu a visualização da área temática, viabilizou a definição dos construtos da pesquisa e os supostos relacionamentos entre eles. Os procedimentos centrais foram o levantamento de referências bibliográficas, a revisão dos textos selecionados e a identificação de possíveis escalas para a mensuração.

Os pesquisadores decidiram que a coleta de dados seria por meio de questionário estruturado e que ele seria dividido em duas partes: a primeira parte trazendo questões so- bre dados demográficos e socioeconômicos dos respondentes; a segunda parte envolvendo as questões dos construtos do estudo - a escala de valor percebido do preço do produto (DE TONI; MAZON, 2014) com seis itens e a escala ServQual (PARASURAMAN; ZEITAML; BERRY, 1985) com 22 itens divididos em cinco importantes aspectos de qualidade: elementos tangíveis, confiabilidade, responsividade, segurança, empatia.

Todas as variáveis foram mensuradas em uma escala do tipo Likert de 5 pontos com extremos de 1 para "discordância total" e 5 para a "concordância total". Em seguida, decidiu-se que um estudo de campo seria desenvolvido em quatro supermercados compactos na Cidade de Goiás (GO). A coleta de dados ocorreu entre outubro e novembro de 2019 , constituída por 160 pessoas abordadas nas filas dos caixas dos supermercados, sendo $19 \%$ dos respondentes abordados no supermercado A; $26 \%$ dos respondentes abordados no supermercado B; $29 \%$ dos respondentes abordados no supermercado C; e $25 \%$ dos respondentes abordados no Supermercado D. A partir daí, procedeu-se uma avaliação exploratória, com a verificação da existência de valores atípicos e valores faltantes. Esse procedimento não indicou a necessidade de exclusão ou de entradas de variáveis.

Os quadros de 2 a 6 apresentam os itens desenvolvidos por Parasuraman, Zeitaml e Berry (1985), os quais representam a escala proposta por estes.

Quadro 2 - Elementos Tangíveis (ET)

\begin{tabular}{|l|l|}
\hline 1 & O supermercado apresenta equipamentos em boas condições (leitores de preços, carrinhos, balanças, etc.). \\
\hline 2 & As instalações físicas desse supermercado são agradáveis (limpeza, corredores, gôndolas, etc.). \\
\hline 3 & Os funcionários possuem boa aparência (uniformes, higiene pessoal, etc.). \\
\hline 4 & Nesse supermercado, os materiais de comunicação são de qualidade (sinalização, cartazes, panfletos, etc.). \\
\hline
\end{tabular}

Fonte: Parasuraman, Berry e Zeitaml (1985).

Quadro 3 - Responsividade (Resp.)

\begin{tabular}{|l|l|}
\hline 5 & O supermercado apresenta informações exatas por parte dos funcionários (preços, serviços, prazos, etc.). \\
\hline 6 & Nesse supermercado, os clientes são prontamente atendidos. \\
\hline 7 & Nesse supermercado, os funcionários estão sempre dispostos para ajudar os clientes. \\
\hline 8 & O supermercado está sempre disponível para atender às solicitações dos clientes. \\
\hline
\end{tabular}

Fonte: Parasuraman, Berry e Zeitaml (1985). 
Quadro 4 - Confiabilidade (Conf.)

9 O supermercado cumpre os prazos divulgados (serviços, ofertas, promoções, etc.).

10 O prazo de entrega em domicílio é feito no prazo combinado.

11 Nesse supermercado, os funcionários se interessam em resolver os problemas dos clientes.

12 Os serviços oferecidos pelo supermercado são confiáveis.

13 O cadastro dos clientes é mantido de forma atualizada e correta.

Fonte: Parasuraman, Berry e Zeitaml (1985).

Quadro 5 - Segurança (Seg.)

14 Os funcionários apresentam postura que inspira confiança nos clientes.

15 Os funcionários desse supermercado conseguem inspirar segurança ao solucionar as dúvidas dos clientes.

16 Os funcionários possuem conhecimento daquilo que fazem.

17 Os funcionários do supermercado são cordiais com os clientes.

Fonte: Parasuraman, Berry e Zeitaml (1985).

Quadro 6 - Empatia (Empat.)

18 Nesse supermercado, recebo atenção individualizada.

19 O horário de funcionamento é conveniente para atender aos clientes.

20 Esse supermercado consegue atender às minhas necessidades específicas.

21 Nesse supermercado, os funcionários prestam atendimento personalizado.

22 Nesse supermercado, os interesses do cliente são tratados com prioridade.

Fonte: Parasuraman, Berry e Zeitaml (1985).

Os pesquisadores também decidiram utilizar uma escala de localização (quadro 7), por ser uma importante variável no âmbito do varejo para a atração do público-alvo (BOONE; KURTZ, 1998).

Quadro 7 - Localização (Loc.)

23 Existe facilidade de acesso ao supermercado (ruas, avenidas, veículos, etc.).

24 A distância é um aspecto que interfere na escolha desse supermercado.

25 Esse supermercado está bem localizado.

Fonte: elaborado pelos autores.

Os itens de valor percebido do preço do produto desenvolvidos por De Toni e Mazon (2014) estão apresentados no quadro 8.

Quadro 8 - Valor Percebido do preço do produto (VP)

26 O dinheiro que gastaria com este produto seria bem gasto.

27 O velho ditado "Você recebe o que você paga" é verdadeiro para este produto.

28 O conjunto de benefícios deste produto é compatível com o conjunto de sacrifícios realizados.

29 O benefício que obteria na compra deste produto é muito alto.

30 O preço deste produto é adequado ao que eu recebo pelo meu dinheiro.

31 Considero que o preço deste produto expressa o real valor no mercado.

Fonte: De Toni e Mazon (2014). 
O quadro 9 apresenta as variáveis sociodemográficas utilizadas nesta pesquisa.

Quadro 9 - Variáveis sociodemográficas

\begin{tabular}{|l|l|}
\hline 32 & Frequência \\
\hline 33 & Faixa Etária \\
\hline 34 & Estado Civil \\
\hline 35 & Gênero \\
\hline 36 & Nível de Escolaridade \\
\hline
\end{tabular}

Fonte: elaborado pelos autores.

As hipóteses da pesquisa são descritas como:

H1: Os aspectos tangíveis do serviço influenciam, positivamente, a percepção de valor;

$\mathrm{H} 2$ : A responsividade do serviço influencia, positivamente, a percepção de valor;

H3: A confiabilidade do serviço influencia, positivamente, a percepção de valor;

H4: A segurança do serviço influencia, positivamente, a percepção de valor;

H5: A empatia do serviço influencia, positivamente, a percepção de valor;

H6: A localização influencia, positivamente, a percepção de valor.

Após a avaliação exploratória da coleta de dados, decidiu-se proceder à análise das hipóteses. A regressão linear múltipla foi a técnica estatística utilizada, pois permite verificar, simultaneamente, todas as hipóteses da pesquisa, além de verificar a importância relativa de cada uma delas sobre o valor percebido do preço do produto no processo de desenvolvimento da vantagem competitiva em supermercados compactos (HAIR et al., 2005). A regressão linear múltipla é uma das técnicas estatísticas mais utilizadas por pesquisadores em ciências sociais aplicadas, mormente nas pesquisas em marketing para estudar relações entre variáveis com o objetivo de predição (MALHOTRA, 2001).

A regressão linear múltipla é uma ferramenta estatística que utiliza a relação de mais de duas variáveis, de forma que uma variável dependente (resposta) possa ser explicada por essas (NETER, 1996). Foi considerado o valor percebido do preço do produto como variável dependente (quadro 8) e as variáveis relacio- nadas nos quadros de 2 a 7 , como as independentes. Como as variáveis preditoras (quadros 2 a 7) são validadas na literatura, todas foram incluídas, ao mesmo tempo, no modelo de regressão linear múltipla pelo método enter de entrada de variáveis.

Para além da regressão linear múltipla, os pesquisadores analisaram, por meio da média, as características sociodemográficas dos respondentes e, mediante a técnica de tabela cruzada, realizaram o cruzamento dos supermercados com as variáveis independentes da pesquisa para verificação nos níveis de qualidade percebida (tabela 3). Para ambas as análises, utilizou-se a recomendação de Costa et al. (2009). Quando se utiliza escala likert de 5 pontos, deve-se adotar que valores de média até 3 são considerados baixos, de 3 a 4 são considerados intermediários, e de 4 a 5 são avaliados como elevados. Todos os procedimentos estatísticos foram realizados no software MiniTab versão 19.

\section{APRESENTACÃO DOS DADOS E DISCUSSÃO DOS RESULTADOS}

\subsection{APRESENTAÇÃO DOS DADOS}

A tabela 1 apresenta os coeficientes estimados $(\beta)$ da relação entre as variáveis independentes e a dependente. O p.valor apresenta a significância de cada relação. Os testes de Fator de Inflação da Variância (VIF) confirmam a ausência de multicolinearidade entre as variáveis independentes, pois $\mathrm{VIF}<5$ (CORRAR; PAULO; DIAS FILHO, 2009). 
Tabela 1 - Coeficientes do modelo selecionado

\begin{tabular}{c|c|c|c|c}
\hline Construtos & Coeficiente $\boldsymbol{\beta}$ & Estatística t & Sig. (p. valor) & VIF \\
\hline Constante & 1,2 & 4,31 & 0,0000 & --- \\
\hline Tangíveis & $-0,1355$ & $-1,58$ & 0,1000 & 2,77 \\
\hline Responsividade & 0,360 & 3,07 & 0,0020 & 4,82 \\
\hline Confiabilidade & 0,055 & 0,47 & 0,6380 & 3,67 \\
\hline Segurança & 0,014 & 0,14 & 0,8880 & 4,24 \\
\hline Empatia & 0,219 & 2,12 & 0,0350 & 3,11 \\
\hline Localização & 0,0959 & 1,54 & 0,1000 & 1,15 \\
\hline
\end{tabular}

Fonte: dados da pesquisa.

O coeficiente de determinação $\left(\mathrm{R}^{2}\right)$ do modelo de regressão selecionado apresentado na tabela 2 evidencia que, aproximadamente, $38 \%$ da variância do valor percebido do preço do produto é explicada pelas variáveis independentes. $O$ valor do erro-padrão da estimativa é de 0,5 . Um valor baixo assim indica que as observações estão próximas da linha ajustada.

Tabela 2 - Indicadores de ajuste para o modelo selecionado

\begin{tabular}{c|c|c}
\hline $\mathbf{R}^{\mathbf{2}}$ & $\mathbf{R}^{\mathbf{2}}$ ajustado & Erro-Padrão da Estimativa \\
\hline 0,3793 & 0,3550 & 0,5000 \\
\hline
\end{tabular}

Fonte: dados da pesquisa.

\subsection{DISCUSSÃO DOS RESULTADOS}

A amostra foi constituída de 160 respondentes abordados nas filas dos caixas dos quatro supermercados compactos da Cidade de Goiás (GO). Quanto à faixa etária da população de respondentes pesquisada, verificou-se que $41,87 \%$ têm entre 18 e 29 anos; $15 \%$ têm entre 30 e 39 anos; $12,5 \%$ têm idade entre 40 e 49 anos; $14,38 \%$ têm idade entre 50 e 59 anos; e $16,25 \%$ têm idade entre 60 anos ou mais de idade. Verificou-se que, independentemente da faixa etária, majoritariamente houve uma percepção intermediária de valor percebido do preço do produto $(3,0<X \leq 4,0)$ pela população pesquisada.

Quanto à frequência com que vão ao supermercado, 59\% dos respondentes vão uma ou mais vezes por semana; $26 \%$ vão duas vezes por mês; $12 \%$ vão uma vez por mês, e 3\% da amostra demoram mais de um mês para ir ao supermercado. Verificou-se que $67,36 \%$ das pessoas que frequentam supermercados até duas vezes por mês têm percepção intermediária de valor percebido do preço do produto $(3,0<X \leq 4,0)$, enquanto $60 \%$ daquelas que demoram mais de um mês para ir ao supermercado têm uma percepção baixa de valor $(\mathrm{X} \leq 3,0)$.

Quanto ao valor percebido do preço do produto, verificou-se que $63,75 \%, 65,52 \%$, $90,90 \%$ e $81,81 \%$ dos clientes dos supermercados $\mathrm{A}, \mathrm{B}, \mathrm{C}$ e $\mathrm{D}$ respectivamente possuem uma percepção intermediária de valor do preço do produto $(3,0<\mathrm{X} \leq 4,0)$.

De acordo com dados sociodemográficos da amostra, 79\% dos respondentes possuem uma renda familiar mensal entre 1 e 3 salários-mínimos. Esses dados conferem com o panorama da renda per capita média da população do município de Goiás (GO), que é de 2,1 salários-mínimos (IBGE, 2018). Do restante, $15 \%$ da amostra possui renda familiar mensal entre 4 a 6 salários-mínimos, 4\% possui renda familiar mensal entre 7 e 9 salários-mínimos; e apenas $2 \%$ dos respondentes possuem renda familiar mensal acima de 10 salários-mínimos. Na comparação entre o valor percebido 
do preço do produto e a renda familiar, verificou-se que famílias com renda de até 9 salários-mínimos têm, majoritariamente, percepção intermediária de valor de preço do produto $(3,0<\mathrm{X} \leq 4,0)$, enquanto as famílias com renda acima de 10 salários têm uma percepção equânime de valor percebido.

Quanto à distribuição por grupo familiar, $65 \%$ dos respondentes pertencem a famílias compostas por até 3 pessoas; $33 \%$ dos respondentes pertencem a famílias compostas de 4 a 6 pessoas; $1 \%$ dos respondentes pertencem a famílias de 7 a 9 pessoas e $1 \%$ dos respondentes pertencem a famílias com mais de 9 pessoas. A comparação entre o construto valor percebido do preço do produto e o grupo familiar demonstrou que $100 \%$ dos grupos familiares com sete pessoas ou mais têm percepção intermediária de valor do preço do produto $(3,0<\mathrm{X} \leq 4,0)$.

Para discussão dos dados da tabela 1 , a leitura do modelo de regressão linear múltipla encontrado é valor percebido do preço do produto $=1,2-0,1355$ (o supermercado possui aspectos tangíveis) $+0,3600$ (o supermercado apresenta aspectos de responsividade) $+0,0550$ (o supermercado apresenta aspectos de confiabilidade) + 0,0140 (o supermercado apresenta aspectos de segurança) + 0,2190 (o supermercado apresenta aspectos de empatia) + 0,0959 (o supermercado apresenta aspectos de localização). (Equação 1).

Dessa forma, verificou-se que, das 6 hipóteses formuladas, H1, H3 e H5 foram refutadas. Das variáveis apresentadas na tabela 1, confiabilidade e segurança possuem nível de significância acima de 0,1 , demonstrando que não se encontram relacionadas, significativamente, com o valor percebido do preço do produto. Esse resultado contraria pesquisas anteriores que verificaram a confiabilidade e a segurança como fatores de relevância como diferenciais de atuação estratégica em MPEs dos setores de comércio e serviços (CUKIER; SILVA, 2012; CUKIER; COSTA, 2013), muito embora, nestes estudos, não se analisou qualidade percebida ao valor de preço percebido de produto.
A hipótese da variável tangíveis (H1) foi refutada, pois o resultado da regressão apresentou o sentido inverso da relação com a variável valor percebido do preço do produto $(\beta=$ $-0,1355, p=0,1)$. Cabe ressaltar que essa verificação contraria estudos de Parasuraman, Berry e Zeithaml (1991), em que a confiabilidade foi um dos fatores considerados importantes, embora, neste estudo, não se tenha analisada a qualidade percebida e suas implicações ao valor de preço percebido de produto.

Os aspectos tangíveis foi o único dos fatores relacionados, negativamente, com nível de valor percebido do preço do produto, reduzindo a estimativa do valor para o nível de valor percebido do preço do produto em 0,1355 desvio-padrão. Na análise descritiva, verificou-se que somente $6,35 \%$ dos entrevistados com renda de até três salários-mínimos possuem uma percepção elevada de valor percebido do preço do produto, o que pode ajudar a justificar essa correlação negativa entre aspectos tangíveis e nível de valor percebido do preço do produto. No modelo proposto por Parasuraman, Zeitaml e Berry (1985), as instalações físicas, o ambiente do supermercado, os funcionários, assim como os materiais de comunicação são atributos percebidos pelos clientes como geradores de valor. Conforme De Toni e Mazon (2014, p. 551), "É certo que o valor percebido per se já incorpora um componente de preço, que está relacionado ao sacrifício monetário ou custo para a obtenção do produto." Com efeito, somente um pequeno percentual de pessoas de baixa renda da pesquisa está disposto a realizar sacrifício monetário para compra de produtos nos supermercados.

Essa relação negativa entre aspectos tangíveis e valor percebido do preço do produto pode ser explicada pelo fato de os clientes perceberem que o conforto, a comodidade e as instalações dos supermercados não correspondem aos preços praticados pelos supermercados da Cidade de Goiás (GO), tornando os aspectos tangíveis incompatíveis com o valor percebido dos preços de produtos praticados no mercado e as rendas familiares na Cidade de Goiás. 
A hipótese (H2) de que a responsividade do serviço contribui, positivamente, para o valor percebido do preço do produto foi aceita com um acréscimo de 0,3600 desvio-padrão, na estimativa do nível de valor percebido do preço do produto $(\beta=0,360, p<0,1)$. A análise descritiva demonstrou que $80,76 \%$ dos entrevistados com 60 anos ou mais de idade possuem nível intermediário de percepção de valor do preço. Nesse caso, devido à elevada faixa etária, há evidências de que os clientes são motivados pela maneira como são atendidos, no que diz respeito à vontade de ajudar por parte dos funcionários, possibilitando um atendimento ágil e pontual. Furuta (2002) e Nascimento (2006) corroboram esse resultado, afirmando que a qualidade no atendimento está relacionada à percepção de valor para o cliente, pois estes buscam estabelecimentos que forneçam atendimento diferenciado.

A hipótese (H3) foi refutada. Embora a confiabilidade na resolução de problemas e nos serviços apresente influência positiva no nível de valor percebido do preço do produto, com acréscimo de 0,055 desvio-padrão, essa relação não foi, estatisticamente, significante $(p=0,638)$, pois $p$-valor $>0,1$.

Assim como ocorreu com a variável confiabilidade, o fato de o supermercado apresentar segurança contribui, positivamente, para a percepção de valor do preço em 0,014 desvio-padrão. Contudo, a hipótese (H4) de que segurança na prestação do serviço contribui, positivamente, para a percepção de valor dos clientes não demonstrou uma relação estatisticamente significante $(\mathrm{p}=0,888)$, pois $\mathrm{p}$-valor $>0,1$.

A hipótese (H5) de que a empatia do serviço contribui, positivamente, para o valor percebido do preço do produto foi comprovada com acréscimo de 0,2190 desvio-padrão e nível de significância aceitável $(\beta=0,219 ; \mathrm{p}<0,1)$. A evidência nesse caso diz respeito aos clientes considerarem a atenção que recebem, tanto por parte dos funcionários, como também da administração do supermercado, na resolução de demandas, o que agrega valor percebido do preço do produto (NASCIMENTO, 2006).

A hipótese (H6) foi comprovada com acréscimo de 0,959 desvio-padrão e nível de significância aceitável $(\beta=0,959 ; \mathrm{p}<0,1)$. Para Porter (1980, 1985), a vantagem competitiva surge por meio das atividades individuais da empresa, sendo a localização considerada um determinante para tal fim. Vários autores concordam que a localização é um mecanismo de atratividade para escolha, retenção e fidelização dos clientes (MASON; MAYER; EZELL, 1991; BOONE; KURTZ, 1998; PARENTE, 2000; MATTAR, 2011; MOREIRA; SOUSA; MOREIRA, 2014). Tendo a Cidade de Goiás (GO) uma vasta área territorial de 3.108,019 $\mathrm{km}^{2}$ (IBGE, 2018), e com 59\% da amostra frequentando os supermercados compactos da cidade uma ou mais vezes por semana (sessão 4.9), a localização das lojas torna-se uma variável importante para influenciar, positivamente, o valor percebido do preço do produto.

A tabela 3 apresenta o cruzamento dos supermercados com as variáveis independentes. Os supermercados ficaram com níveis intermediários de percepção quanto às variáveis preditoras de valor do preço do produto.

Tabela 3 - Supermercados X Variáveis Independentes da Pesquisa

\begin{tabular}{c|c|c|c|c|c|c}
\hline Supermercado & ET. & Resp. & Conf. & Seg. & Empat. & Loc. \\
\hline A & 3,6612 & 3,5645 & 3,6903 & 3,6935 & 3,4000 & 3,7526 \\
\hline B & 3,9583 & 4,0000 & 3,7952 & 4,0000 & 3,8428 & 3,9047 \\
\hline C & 4,0000 & 4,0543 & 4,0000 & 4,1358 & 3,7739 & 3,5217 \\
\hline D & 3,1463 & 3,1890 & 3,2439 & 3,1402 & 3,0000 & 3,4390 \\
\hline
\end{tabular}

Fonte: dados da pesquisa. 
Daft (1999, p. 149) destaca que "a competência essencial de uma empresa é alguma coisa que a organização faz essencialmente bem em comparação com os seus concorrentes". Logo, as variáveis da escala ServQual nem a variável localização não foram elementos importantes de diferenciação entre os supermercados concorrentes.

\section{CONCLUSÕES, SUGESTÕES E RECOMENDAÇÕES}

O objetivo do artigo foi identificar a influência da qualidade percebida sobre o valor percebido do preço do produto no processo de desenvolvimento da vantagem competitiva em supermercados compactos. Para tanto, coletaram-se dados de uma amostra de 160 clientes distribuídos em quatro supermercados compactos na Cidade de Goiás (GO). A técnica de regressão linear múltipla foi adequada para responder à pergunta da pesquisa, uma vez que o modelo gerado (equação 1) demonstrou que os supermercados compactos possuem aspectos da qualidade percebida representados pela responsividade, empatia e tangíveis, além da variável localização, como fatores relacionados ao valor percebido do preço do produto.

O objetivo da pesquisa foi alcançado, pois se demonstrou a influência dos fatores da qualidade percebida no valor percebido do preço do produto em supermercados compactos. Contudo, os dados da tabela cruzada demonstraram evidências de que responsividade, empatia, tangíveis e localização (tabela 3) não podem ser consideradas fontes geradoras de vantagem competitiva para nenhum desses supermercados concorrentes; ou seja, os supermercados analisados não destoam entre si quanto à criação de valor por meio de estratégias na qualidade de serviços, o que gera uma aproximação em nível estratégico entre eles. Com efeito, os gestores precisam desenvolver novas ações estratégicas para a geração de valor se quiserem obter maior participação de mercado nesse setor de baixas barreiras de entrada, principalmente em época de crise eco- nômica em que a sobrevivência do negócio é sensibilizada.

Desde os anos 1990, os supermercados brasileiros vêm readequando as estruturas dos seus negócios e realizando investimentos na busca por eficiência operacional e técnica em ações que demonstram a capacidade de resposta aos movimentos da demanda. Contudo, ainda é incipiente o investimento dos supermercados compactos em melhorias da qualidade de atendimento ao cliente por meio de comércio eletrônico. Da mesma forma com que, nos anos 1990, a automação na frente de loja com leitores ópticos nos caixas e a utilização de sistema de distribuição com transferência eletrônica de informação entre computadores sofisticaram o setor de varejo de autosserviço brasileiro, é provável que investir no atendimento ao cliente por meio de comércio eletrônico amplie o valor percebido do preço do produto no processo de desenvolvimento da vantagem competitiva em supermercados compactos.

A primeira indicação de pesquisa futura é comparar o desempenho de supermercados que utilizam a estratégia de vendas online com aqueles que não a adotam. Para isso, é sugerido utilizar uma métrica comparativa do desempenho dos supermercados (Faturamento bruto, ROA, participação de mercado, entre outras), o que permitiria melhor explicar o posicionamento dos empreendimentos mediante a exploração de competências, percepção de mercado e de oportunidades.

Outra indicação de pesquisa futura é verificar o porquê de grande parcela dos clientes que recebem até três salários-mínimos terem manifestado uma percepção intermediária de valor percebido no preço do produto. Será que pode ser a sensibilização econômica? Será que consumidores com maior poder econômico desprezam os fatores aqui mencionados? (O que levaria a entender estratégias diferentes para níveis socioeconômicos diferentes). Também cabe analisar em pesquisa futura que envolva supermercados compactos as razões da confiabilidade e segurança não serem significativas para o valor percebido, haja vista serem fato- 
res que, em geral, são significantes (FURUTA, 2002; NASCIMENTO, 2006).

Outra limitação da pesquisa é terem sido analisados somente supermercados da Cidade de Goiás (GO), o que impede a generalização dos resultados para além da cidade. Devido à representatividade do setor de varejo de autosserviço para a economia nacional, sugere-se ampliar a pesquisa para outros municípios, como oportunidade de trabalhos futuros, com vistas a abordagens mistas dos fatores da pesquisa.

\section{REFERÊNCIAS}

AILAWADI, K.L.; KELLER, K.L. Understanding retail branding: conceptual insights and research priorities. Journal of Retailing, v. 80, n. 4, p. 331-342, 2004.

BARBANTE, L. A. J. et al. Estratégias de Marketing e Vantagem Competitiva: Estudo de Caso das Vendas de Seminovos da Concessionária Toyopar em Londrina-pr. In: SIMPÓSIO DE EXCELÊNCIA EM GESTÃO E TECNOLOGIA, 2012, Rio de Janeiro. Anais [...]. Rio de Janeiro: Seget, 2012. p. 1- 6.

BARNEY, J. B.; HESTERLY, W. S. Administração estratégica e vantagem competitiva. São Paulo: Pearson Prentice Hall, 2007.

BARROS, A. S. As centrais de negócios como alternativa de estratégia competitiva dos pequenos e médios supermercados: estudo de caso da rede litoral de supermercados. 2007. Dissertação (Mestrado em Organização e gestão) - Universidade Católica de Santos, Santos, SP, 2007.

BLACKWELL, R. D.; MINIARD, P. W.; ENGEL, J. F. Comportamento do consumidor. Tradução Eduardo Teixeira Ayrosa. São Paulo: Pioneira Thomson Learning, 2005.

BOLTON, L. E.; WARLOP, L.; ALBA, J. W. Consumer perceptions of price (un)fairness.
Journal of Consumer Research, v. 29, n. 4, p. 474-491, 2003.

BOONE, L. E.; KURTZ, D. L. Marketing contemporâneo. Rio de janeiro: LCT. BNDES. Comércio varejista supermercados, 1998.

BRITO, R. P.; BRITO, L. A. L. Vantagem Competitiva e sua Relação com o Desempenho - uma Abordagem Baseada em Valor. RAC, v. 16, n. 3, p. 360-380, 2012.

CARCANHOLO, M. D. A importância da categoria valor de uso na teoria de Marx. PESQUISA \& DEBATE, São Paulo, v. 9, n. 2, p. 17-43, 1998.

COLLA, J. E. et al. Alinhamento das ações estratégicas em uma pequena empresa supermercadista paranaense. Revista de Administração IMED, v. 3, n. 3, p. 146-162, 2013.

CORRAR, L. J.; PAULO, E.; DIAS FILHO, J. M. (coord.). Análise multivariada: para cursos de administração, ciências contábeis e economia. São Paulo: Atlas, 2007.

COSTA F. J. et al. Uma análise do interesse de estudantes de administração pela área de marketing. Revista de Negócios, v. 14, n. 3, p. 54-71, 2009.

CUKIER, R.; SILVA, O. R. Análise dos gaps da qualidade de serviços medido pelo modelo servqual em farmácia de manipulação. ENIAC Pesquisa, v. 1, n. 1, p. 77-91, 2012.

CUKIER, R.; COSTA, M. A. M. da. Disfunção Competitiva: análise do nível das lacunas (Gaps), pelo modelo Servqual, em farmácias de manipulação em municípios do Estado de São Paulo. Revista Científica Hermes, v. 8, p. 7091, 2013.

DAFT, R, L. Administração. 4. ed. Rio de Janeiro: LTC Editora, 1999. 
DALONGARO, R. C.; PIRES, D. B.; FROEMMING, L. M. S. Análise do cenário mercadológico com os supermercados em uma região de fronteira. REVISTA GESTO, v 3, n. 1, p. 18-30, 2015.

DE TONI, D.; MAZZON, J. A. Imagem de preço de produto: proposição de um modelo conceitual. Revista de Administração - RAUSP, v. 48, n. 3 , p. $454-468,2013$.

DE TONI, D.; MAZZON, J. A. Teste de um modelo teórico sobre o valor percebido do preço de um produto. Revista de Administração - RAUSP, v. 49, n. 3, p. 549-565, 2014.

FERREIRA, M.; VENÂNCIO, M.; ABRANTES, L. Análise da eficiência do setor de supermercados no Brasil. Economia Aplicada, v. 13, n. 2, p. 333-347, 2009.

FLORIANI, D. O grau de internacionalização, as competências e o desempenho da PME brasileira. 2010. Tese (Doutorado em Administração) - Universidade de São Paulo USP, São Paulo, 2010.

FURUTA, E. C. Razões de escolha de supermercado de vizinhança como local de compra. São Paulo: USP, 2002.

GARCIA, L. M. B. Coesão relacional e mecanismos formais e informais de coordenação em redes de supermercados de pequeno porte no estado de São Paulo. 2011. 292 f. Tese (Doutorado) - Universidade Federal de São Carlos, São Carlos, 2011.

GARVIN, D. A. Gerenciando a qualidade: a visão estratégica e competitiva. Rio de Janeiro: Qualitymark, 1992.

GENNARI, A. M. Globalização, Neoliberalismo e Abertura Econômica no Brasil nos Anos 90. Pesquisa \& Debate, v. 13 , n. 21 , p. 30-45, 2002.
GUEDES, A. A. et al. Capacidades Dinâmicas e Vantagens Competitivas: Um Estudo em uma Construtora Com Foco No Mercado Baixa Renda. Caderno de Administração, v. 24, n. 2, 29-44, 2016.

HALFIN, R. Inovação em Serviços no Segmento de Supermercados: um estudo das inovações realizadas no setor a partir da análise das competências das empresas e seus reflexos sobre as condições de atendimento. 2007. $99 \mathrm{f}$. Dissertação (Mestrado) - Universidade Plesbeteriana Mackenzie, São Paulo, 2007.

HERMES, L, C, R.; CRUZ, C. M. L.; SANTINI, L. Vantagens Competitivas do Mix de Varejo sob a Ótica da VRIO: um Estudo de Caso em um Supermercado Independente. Brazilian Journal of Marketing, v. 15, n. 3, p. 373-389, 2016.

HOFFMANN, A. S. A percepção da qualidade na prestação de serviços públicos: estudo de caso da Niterói Terminais Rodoviários - NITER. 2006. Dissertação (Mestrado em Administração) - Universidade Estácio de Sá, Rio de Janeiro, 2006.

IBGE. Trabalho e Rendimento. 2018. Disponível em: https://cidades.ibge.gov.br/brasil/go/ goias/panorama. Acesso em: 5 out. 2020.

ITO, N. C. et al. Valor e Vantagem Competitiva: Buscando Definições, Relações e Repercussões. Revista de Administração Contemporânea, v. 16, n. 2, p. 290-307, 2012.

KAPLAN, S R.; NORTON P. D. A estratégia em ação: balanced scorecard. 4. ed. Rio de Janeiro: Campus, 1997.

MACOWSKI, D. H. A qualidade dos serviços prestados por uma instituição de ensino superior pública na visão dos graduandos: análise estatística segundo o método SERVQUAL. 2007. Dissertação (Mestrado em Métodos Numéricos em Engenharia). Universidade Federal 
do Paraná, Curitiba, 2007.

MALHOTRA, K. N. Pesquisa de marketing: uma orientação aplicada. 3. ed. Porto Alegre: Bookman, 2001.

MASON, J. B.; MAYER, M. L; EZELL, L. Retailing. New York: Richard Irwin \& Sons, 1991.

MATTAR, F. N. Administração de Varejo. Rio de Janeiro: Campus, 2011.

MONROE, K.B. Pricing: making profitable decisions. New York: McGraw-Hill, 1990.

MOREIRA, H. S.; SOUSA, C. V.; MOREIRA, M. A. Marketing de Varejo em Ambiente Competitivo: Estratégias Adotadas por Pequenos Varejistas Supermercadistas da Região Metropolitana de Belo Horizonte/MG. In: ENCONTRO DE ESTUDOS EM EMPREENDEDORISMO E GESTÃO DE PEQUENAS EMPRESAS, 8., 2014, Goiânia. Anais [...]. Goiania: Egepe, 2014. Disponível em: http://www.egepe.org.br/ anais/tema03/74.pdf. Acesso em: 1 maio 2020.

NASCIMENTO, C. A. X. D. Fatores determinantes da qualidade percebida na comercialização de carne bovina fresca em supermercados de Campo Grande/MS. 2006.

Dissertação (Mestrado em Agronegócios) Universidade Federal de Mato Grosso, Campo Grande, Mato Grosso, 2006.

NETER, J. et al. Applied Linear Statistical Models. Boston, MA: McGraw-Hill, 1996.

NUNES FILHO, R. Sempre adiante, apesar dos desafios. Superhiper, v. 45, n. 514, p. 14-17, 2019.

PARASURAMAN, A. P.; ZEITHAML, V. A.; BERRY, L. L . A Conceptual Model of Service Quality and its Implication for Future Research (SERVQUAL). Journal of Marketing, v. 49, p. $1-50,1985$.

PARASURAMAN A, P.; BERRY L. L.; ZHEITMAL V. A. Refinement and reassessement of the SERVQUAL dimensions. J Retailing, v. 67, n. 4, p. 420-50, 1991.

PARENTE, J. Varejo no Brasil: Gestão e Estratégia. São Paulo: Atlas, 2000.

PITELIS, C. N. The Co-Evolution of Organizational Value Capture, Value Creation and Sustainable Advantage. Organization Studies, v. 30, n. 10, p.1115-1139, 2009.

PORTER, M. E. Competitive strategy: techniques for analysing industries and competitors. New York: Free Press, 1980.

PORTER, M. E. Competitive advantage: creating and sustaining competitive performance. New York: Free Press, 1985.

QUEIROZ, T. S.; SOUZA, T.; GOUVINHAS, R. P. Estratégia de marketing como um diferencial na escolha do supermercado de bairro. Revista de Administração Mackenzie, v. 9, n. 3, p. 58-84, 2008.

ROJO, F. J. G. Qualidade total: uma nova era para os supermercados. Revista de Administração de Empresas, v. 38, n. 4, p. 26-36. 1998.

SANDRONI, P. Novíssimo Dicionário de Economia. São Paulo: Best Seller, 1999.

SANTOS, A, L. dos; KREIN, J. D.; CALIXTRE, A. B. (coord.). Micro e Pequenas

Empresas Mercado de Trabalho e Implicação para o Desenvolvimento. Rio de Janeiro: IPEA, 2012. Disponível em:

http://www.ipea.gov.br/agencia/images/stories/ PDFs/livros/livros/livro_micro_pequenasemp resas.pdf. Acesso em: $1 \overline{7}$ abr. 2020.

SANTOS, A. C.; ROSALEM, V. Qualidade 
como Vantagem Competitiva: um Estudo em Empresa Atacadista. In: SIMPOSIO DE EXCELÊNCIA EM GESTÃO E TECNOLOGIA, 2006, Resende, RJ. Anais [...]. Resende, RJ.: SEGET, 2006. Disponível em: https://www. aedb.br/seget/arquivos/artigos06/596_QUALIDADE\%20COMO\%20VANTAGEM \%20 COMPETITIVA.pdf. Acesso em: 1 maio 2020.

SALUNKE, S.; WEERAWARDENA, J.; MCCOLL-KENNEDY, J. R. Towards a model of dynamic capabilities in innovation-based competitive strategy: insights from project-oriented service firms. Industrial Marketing Management, v. 40, p. 1251-1263, 2011.

SESSO FILHO, U. A. O setor supermercadista no Brasil nos anos 1990. 2003. Tese (Doutorado) - Escola Superior de Agricultura "Luiz de Queiroz", Universidade de São Paulo, São Paulo, 2003.

SILVEIRA, J. A.; LEPSCH, S. L. Alterações recentes na economia do setor supermercadista brasileiro. Revista de Administração, v. 32, n. 2, p. 5-13, 1997.

SMITH, A. The wealth of nations. In: RAPHAEL, D. D.; MACFIE, A. L. (ed.). The Glasgow edition of the works and correspondence of Adam Smith. Oxford: Claredon Press, 1976.

THEODORIDIS, P.; CHATZIPANAGIOTOU, $\mathrm{K}$. Store image attributes and customer satisfaction across different customer profiles within the supermarket sector in Greece. European Journal of Marketing, v. 43, n. 5/6, p. 708734, 2009.

TOALDO, A. M. M.; ABEL SOBRINHO, Z.; CAMARGO, S. M. Processo de formulação de layouts em supermercados convencionais no Brasil. REGE, v. 17, n. 4, p. 451-469, 2010.

TOLEDO, G. L.; MORETTI, S. L. DO A. Valor para o Cliente e Valor do Cliente: Conceitos e Implicações para o Processo de Marketing.
Desenvolvimento em Questão, v. 14, n. 35, p. 400-419, 2016.

VASCONCELOS, F. C.; CYRINO, A. B. Vantagem competitiva: os modelos teóricos atuais e a convergência entre estratégia e teoria organizacional. Revista de Administração de Empresas, São Paulo, v. 40, n. 4, p. 20-37, out./ dez. 2000.

WERNER, A.; SEGRE, L. M. Estratégias, competências e crescimento: uma visão sobre o segmento de supermercados. In: ENCONTRO NACIONAL DA ASSOCIAÇÃO NACIONAL DOS PROGRAMAS DE PÓS-GRADUAÇÃO EM ADMINISTRAÇÃO, 25., 2001, Campinas. Anais [...]. São Paulo: ANPAD, 2001. Disponível em: http://www.anpad.org.br/ admin/pdf/enanpad2001-eso-839.pdf. Acesso em: 2 maio 2020.

WILDER, A. Mudanças no setor supermercadista e a formação de associações de pequenos supermercados. 2003. 208 f. Dissertação (Mestrado) - Escola Superior de Agricultura "Luiz de Queiroz", Universidade de São Paulo, 2003.

WOERTER, M.; ROPER, S. Openness and innovation - Home and export demand effects on manufacturing innovation: Panel data evidence for Ireland and Switzerland. Research Policy, v. 39, p. 155-164, 2010. 